\title{
Influence of the addition of different ingredients on the bioaccessibility of glucose released from rice during dynamic in vitro gastrointestinal digestion
}

\author{
Jean-Michel Fernandes, Daniel Alexandre Madalena, António Augusto Vicente and Ana Cristina Pinheiro \\ CEB - Centre of Biological Engineering, University of Minho, Braga, Portugal
}

\begin{abstract}
Rice represents a primary source of carbohydrates in human nutrition. Upon its consumption, the released sugars are mostly absorbed, categorising rice as a high glycemic index food. Addition of ingredients is common practice when cooking rice, which may affect rice digestibility and influence nutrients absorption in the gastrointestinal (GI) tract, enabling a controlled glucose release. In this sense, rice formulations were submitted to a dynamic in vitro Gl model, constituted by reactors that simulates peristalsis coupled to filtration membranes, to evaluate carbohydrates hydrolysis and bioaccessibility. Addition of quinoa and wholegrains reduced carbohydrates hydrolysis (i.e. $38.5 \pm 5.08 \%$ and $57.98 \pm 1.91 \%$, respectively) and glucose bioaccessibility (i.e. $25.92 \pm 5.70 \%$ and $42.56 \pm 1.39 \%$, respectively) when compared with brown rice (i.e. $63.86 \pm 2.96 \%$ hydrolysed and $44.33 \pm 1.88 \%$ absorbed). Addition of vegetables significantly decreased sample chewiness and resulted in superior hydrolysis $(71.75 \pm 7.44 \%)$ and glucose absorption (51.61 $\pm 6.25 \%)$.
\end{abstract}

ARTICLE HISTORY

Received 9 January 2020

Revised 7 April 2020

Accepted 29 April 2020

\section{KEYWORDS}

Brown rice digestibility;

wholegrains and

vegetables; dynamic gastrointestinal model; glucose-controlled release; carbohydrate hydrolysis

\section{Introduction}

Rice (Oryza sativa) is one of the most abundant foods worldwide that is consumed in a daily basis in high quantities, representing a primary source of carbohydrates in human nutrition. In rice, as well in other cereals and vegetables, sugars are stored as starch molecules, shaped in granule-like form, making up to $90 \%$ of the cereal or grain dry weight (Patindol et al. 2015). Upon digestion, starch is hydrolysed by salivary and intestinal amylases into small glucose molecules that are passible to be absorbed in the small intestine. As such, rice is categorised as a high glycemic index food, because blood glucose levels escalates following rice consumption (Chang et al. 2014). In the case of carbohydrates, the portion of resistant starch is of great interest as it can withstand digestion in the gastrointestinal (GI) tract, thus, reaching the large intestine where it can be fermented by the gut microbiota. Resistant starches have a fibre-like function, and upon fermentation may modulate the production of small short-chain fatty acids which are beneficial in the control of human glucose metabolism (Wong and Louie 2017).

Many studies can be found in the literature on how pre- and post-harvest processes (such as milling (Roy et al. 2008), drying and precooking (Yu et al. 2017), parboiling (Boers et al. 2015), ageing (Azizi et al. 2019), and cooking (Reed et al. 2013)) and structural characteristics (such as amylose/amylopectin ratio (Schirmer et al. 2013), retrogradation (Frei et al. 2003), and starch morphology (Shapter et al. 2008; Tamura et al. 2016)) can affect rice properties and its digestibility. Nevertheless, the rice industry is currently focussing in understanding how the addition of different ingredients can impact the digestibility of rice and consequently its glycemic index.

Rice is often cooked with other added ingredients, like vegetables, cereals, grains, aromatic plants, sauces, among others, altering rice properties in the final product and the food nutritional content by varying the amounts of fibres, proteins and lipids present. As previously referred, dietary fibres are beneficial in the control of glucose release and absorption, and are also known for their health benefits, namely reducing the probability rates of heart diseases, type 2 diabetes, colon cancer, etc., but they also influence how nutrients and chemicals are absorbed in the GI tract (Jha et al. 2017). According to the European Commission (EC) (European Parliment 2011), dietary fibres are defined as 'carbohydrate polymers with three or more monomeric units, which are neither 
digested nor absorbed in the human small intestine'. These types of polysaccharides are naturally present in fruits, vegetables, whole grain cereals, seeds and pulses (Dhingra et al. 2012). Although the consumption of dietary fibres presents many health benefits, it was also known that these structures can interact with other compounds available during digestion, influencing their bioaccessibility and bioavailability. For instance, there is evidence that dietary fibres interact with fruits and vegetables antioxidant compounds (Palafox-Carlos et al. 2011), possibly decreasing their bioaccessibility and bioavailability (Grundy et al. 2016).

Not only dietary fibres influence the digestibility of food. For instance, in most processed and commercial foods, the amount of free sugar is detailed. These added sugars, either monosaccharides or disaccharides, are hydrolysed at different rates depending on their type and source, affecting the digestibility of the food matrix (Nakov et al. 2019). Also, the protein content, responsible for the structure of foods, will interact with the remaining macronutrients in the food matrix. It has been demonstrated that protein interactions with starch, fibre and phenolic compound reduced hydrolysis of carbohydrates (Gularte et al. 2012; Świeca et al. 2014; Opazo-Navarrete et al. 2019). Finally, many ingredients (i.e. seed, pulses, beans, etc.) contain minor quantities of antinutrients, such as saponins, phytic acid, tannins, nitrates and oxalates, which may inhibit amylase, pancreatin or trypsin activity, and, therefore, may reduce the length and extensions of carbohydrates digestion (Alonso et al. 2000; Filho et al. 2017).

In this sense, understanding the effects of ingredients on the digestibility of food could permit to achieve a controlled glucose release from carbohydrates based foods. This controlled glucose release would be modulated through the addition of said ingredients or nutrients, that ultimately could lead to lower carbohydrates hydrolysis and, consequently, to a lower glycaemic index.

To better understand nutrients interactions during carbohydrates digestion, dynamic in vitro GI systems can be used. These systems allow the simulation of the conditions found in the human GI tract dynamically, through the use of reactors which simulate the stomach, duodenum, jejunum and ileum and mimic peristaltic movements. These systems are also often coupled with filtration membranes which are able to filter small molecules, such as glucose, providing insight on the bioaccessibility of some compounds. Also, GI parameters for digestive fluids and enzymes were described and validated in an international consensus by INFOGEST (Brodkorb et al. 2019).

In this sense, the addition of nutrients in whole grain rice formulations was evaluated to understand their influence on carbohydrates' hydrolysis and consequential glucose bioaccessibility during digestion, through the use of a dynamic in vitro gastrointestinal digestion system (DIVGIS).

\section{Materials and methods}

\section{Rice samples}

Samples used in this work were commercially available ready-to-eat rice formulations from Pato Real Nutriminuto (Ernesto Morgado, Portugal). All formulations were constituted by Carolino brown rice, a long grain Japonica-type rice variety from Portugal. Four ready-to-cook formulations with the following ingredients were tested: Brown Rice (BR), containing rice $(51 \%)$, water, olive oil and salt; Brown Rice and Quinoa (Q), containing rice (53\%), red and white quinoa (5.1\%), water, olive oil and salt; 5 Wholegrains Mix (WM), containing rice (46\%), buckwheat (3.7\%), millet (2.6\%), red quinoa (1.5\%) and chia (1.5\%), water, olive oil and salt; and Brown Rice, Veggies and Seeds (VS), containing rice (41\%), peas (9.4\%), carrots (6.5\%), sweetcorn (6.5\%) and golden flaxseeds (2.3\%), water, olive oil, garlic and salt. These formulations were preprocessed and are thus sold ready to cook during $1 \mathrm{~min}$ at $800 \mathrm{~W}$ in a microwave oven, upon which they can be consumed. Nutrition declaration of each formulation is described in Table 1.

Table 1. Nutrition declaration of Pato Real Nutriminuto formulations corresponding to a portion of $100 \mathrm{~g}$.

\begin{tabular}{|c|c|c|c|c|}
\hline & $\begin{array}{l}\text { Brown } \\
\text { rice }(B R)\end{array}$ & $\begin{array}{c}\text { Brown rice } \\
\text { and Quinoa }(\mathrm{Q})\end{array}$ & $\begin{array}{l}5 \text { Wholegrains } \\
\text { mix (WM) }\end{array}$ & $\begin{array}{c}\text { Brown rice, veggies } \\
\text { and seeds (VS) }\end{array}$ \\
\hline \multirow[t]{2}{*}{ Carbohydrates (of which sugars) (g) } & 33.2 & 38.8 & 39.5 & 30.4 \\
\hline & 0.4 & 0.8 & 0.6 & 1.7 \\
\hline \multirow[t]{2}{*}{ Lipids (of which saturates) (g) } & 2.9 & 4.4 & 4.4 & 5.5 \\
\hline & 0.4 & 0.6 & 0.7 & 0.7 \\
\hline Fibres (g) & 2.1 & 3.1 & 3.0 & 3.4 \\
\hline Proteins $(\mathrm{g})$ & 3.2 & 4.7 & 5.3 & 4.4 \\
\hline Salt (g) & 0.4 & 0.6 & 0.5 & 0.6 \\
\hline Energy (kcal) & 176 & 220 & 225 & 195 \\
\hline
\end{tabular}




\section{Reagents}

Reagents used for total starch determination, namely thermostable $\alpha$-amylase $(3.000 \mathrm{U} / \mathrm{mL}$ on Ceralpha reagent at $\mathrm{pH} 6.5)$, amyloglucosidase $(3.300 \mathrm{U} / \mathrm{mL}$ on soluble starch) and GOPOD reagent were purchased from Megazyme Inc. (Megazyme International, Ireland Ltd., Wicklow, Ireland). $\alpha$-Amylase (Roche, Basel, Switzerland, 10102814001) was obtained from Merck (Merck KgaA, Darmstadt, Germany) and pepsin (P7012; CAS 9001-75-6), lipase (L3126, CAS 900162-1), pancreatin (P7545; CAS 8049-47-6) and bile salts (B8631; CAS 8008-63-7) were obtained from Sigma-Aldrich (Sigma-Aldrich Química, S.L., Lisboa, Portugal). Starch from potato (Panreac, 121096.1211) was purchased from Panreac (Panreac Química S.L.U., Barcelona, Spain).

\section{Characterisation of formulations}

Initial characterisation of formulations involved the determination of total starch content, amylose/amylopectin ratio and dry weigh. Each assay was performed in triplicate for each sample type.

The total starch was quantified using the Total Starch Assay Procedure Kit K-TSTA (Megazyme, Wicklow, Ireland) through the amyloglucosidase/ $\alpha$-amylase method. Rice samples were grinded using a mortar and pestle and $100 \mathrm{mg}$ of milled uncooked sample was weighed. Subsequently, $5 \mathrm{~mL}$ of ethanol $80 \%(\mathrm{v} / \mathrm{v})$ were added and the samples were incubated at $80-85^{\circ} \mathrm{C}$ for $5 \mathrm{~min}$. An equal volume of ethanol $80 \%$ was added with subsequent centrifugation at $1800 \mathrm{~g}$ for $10 \mathrm{~min}$ (EBA 20, Hettich, Kirchlengern, Germany). After centrifugation, supernatants were discarded and samples were washed again with the same solution two more times to remove free glucose. Then $2 \mathrm{~mL}$ of $\mathrm{KOH} 2 \mathrm{~mol} \mathrm{~L}^{-1}$ were added and samples were placed in a water bath at $4{ }^{\circ} \mathrm{C}$ under stirring for $20 \mathrm{~min}$. In this step, $\mathrm{KOH}$ functions as a chaotrophic agent, facilitating samples dissolution and subsequent hydrolysis. Subsequently, $\mathrm{KOH}$ was neutralised with the addition of $8 \mathrm{~mL}$ of sodium acetate buffer $1.2 \mathrm{~mol} \mathrm{~L}^{-1}$ ( $\mathrm{pH} \mathrm{3.8).} \mathrm{At} \mathrm{this} \mathrm{point,} 0.1 \mathrm{~mL}$ of thermostable $\alpha$-amylase and $0.1 \mathrm{~mL}$ of amyloglucosidase were added to the samples and placed at $50{ }^{\circ} \mathrm{C}$ under stirring for $30 \mathrm{~min}$, for the hydrolysis of starch into soluble maltodextrins and subsequently hydrolysis to Dglucose. Since cereals present a high starch content $(>10 \%)$, samples were diluted with distilled water up to $100 \mathrm{~mL}$ (Fernandes et al. 2020). The resulting Dglucose was determined using the glucose oxidase-peroxidase (GOPOD) reagent (procedure detailed in
Quantification of released sugars and determination of glycemic index section) and starch percentage was obtained by multiplying by $\frac{162}{180}$ (converting factor of free D-glucose to starch-occurring anhydrous D-glucose).

Amylose content was determined based on the standardised ISO 6647-1, Rice - Determination of amylose content. In summary, $100 \mathrm{mg}$ of milled sample were wet with $1 \mathrm{~mL}$ of ethanol $95 \%(\mathrm{v} / \mathrm{v})$. Afterwards, $9.0 \mathrm{~mL}$ of sodium hydroxide solution at $1 \mathrm{~mol} \mathrm{~L}^{-1}$ was added and samples were placed in a boiling water bath for $10 \mathrm{~min}$. The solution was then made up to $100 \mathrm{~mL}$ with distilled water. $5 \mathrm{~mL}$ of each treated sample were transferred and $2 \mathrm{~mL}$ of iodine solution (iodine $8 \mathrm{mmol} \mathrm{L}^{-1}$ with potassium iodide $0.12 \mathrm{~mol} \mathrm{~L}^{-1}$ ) plus $1 \mathrm{~mL}$ of acetic acid $1 \mathrm{~mol} . \mathrm{L}^{-1}$ were added and made up to $100 \mathrm{~mL}$ with distilled water. After the colour development, the absorbance of samples was read at $620 \mathrm{~nm}$ (V560, Jasco, Cremella, Italy). A calibration curve with pure amylose from potato (Sigma A0512; CAS 9005-82-7) was plotted for calculations of the amylose content, and amylopectin was obtained as the difference between total starch and the determined amylose.

Samples dry weight was determined by drying $2 \mathrm{~g}$ of cooked sample overnight at $105^{\circ} \mathrm{C}$ until a constant weight was attained.

\section{Texture profile analysis of different formulations}

Texture profile analysis (TPA) of the different rice formulations was conducted using a two cycle compression with $70 \%$ strain at a pre-test, test and protest speed of 2,1 and $5 \mathrm{~mm} \mathrm{~s}^{-1}$ with a trigger force of $100 \mathrm{~g}$. For this purpose, the rice samples were cooked according to the label recommendations $(1 \mathrm{~min}$ at $800 \mathrm{~W}$ in a microwave oven) and left to cool at least $1 \mathrm{~h}$ prior to analysis. Approximately $2 \mathrm{~g}$ of rice samples were weighed and arranged in one layer into a metal plate of a double axis texture analyser TA.HD PLUS from Stable Microsystems (Surrey, UK), with a load cell of $30 \mathrm{~kg}$ and a $75 \mathrm{~mm}$ aluminium compression paten attachment (Stable Microsystems, Surrey, UK). The compression curves were then used to calculate the hardness, adhesiveness, springiness, cohesiveness, resilience and chewiness of the samples. All parameters were derived directly from the two compression curves with the exception of chewiness, which corresponds to the multiplication between hardness, cohesiveness and springiness, using the software Texture Exponent ver. 6.1.1.0 by Stable Microsystems (Surrey, UK). At least 10 replicates of 
each rice formulation were used in the TPA analysis. A box plot analysis was used for outlier detection, with a coefficient of 0.5 .

\section{Dynamic in vitro gastrointestinal digestion}

Dynamic in vitro GI digestions were performed by simulating the gastric, duodenal, jejunal and ileal portions of the GI tract with individual reactors in a gastrointestinal system (DIVGIS), described elsewhere (Pinheiro et al. 2016). Digestive parameters were based on the standardised conditions found in international consensus for static (Minekus et al. 2014) and semi-dynamic (Mulet-Cabero et al. 2020) in vitro digestion protocols, detailed below.

\section{Determination of digestion parameters}

To use the DIVGIS, a set of digestive parameters must be initially defined. The amount of food tested was $50 \mathrm{~g}$ of each rice sample that was previously cooked in a microwave oven for $1 \mathrm{~min}$ at $800 \mathrm{~W}$ (MS23K3513AW, Samsung Electronics, London, UK) and grinded in a food grinder (VM-4210, Tristar, Tilburg, Netherlands), mounted with the included fine cutting plate (XX-4210230, Tristar, Tilburg, Netherlands), to ensure a uniform mechanic degradation, as similar as possible to the mastication process. Dry weight of formulations was obtained as described above (see Characterisation of formulations section), which was necessary to determine the volume of simulated salivary fluid (SSF) to be added in the oral phase. The caloric content of food samples (i.e. calories per gram of food) was calculated applying standard Atwater factors, that stipulate $4 \mathrm{kcal}$ for $1 \mathrm{~g}$ of protein and $1 \mathrm{~g}$ of carbohydrates and $9 \mathrm{kcal}$ for $1 \mathrm{~g}$ of lipids. These factors were necessary to calculate the gastric emptying (described through Equations (1)-(3)), since a linear relationship has been found between the caloric content and the delivery rate of intraduodenal calories, which was established to be $2 \mathrm{kcal} / \mathrm{min}$ (Calbet and MacLean 1997):

Energy rate $(\mathrm{kcal} / \mathrm{min})=\frac{\text { Sample }(\mathrm{g})}{\text { In vivo meal }(\mathrm{g})} * 2 \mathrm{kcal} / \mathrm{min}$

Gastric emptying $(\mathrm{min})=\frac{\text { Sample caloric content }(\mathrm{kcal})}{\text { Sample energy rate }(\mathrm{kcal} / \mathrm{min})}$

$$
\begin{aligned}
& \text { Gastric emptying rate }\left(\frac{m L}{m i n}\right) \\
& =\frac{\text { Gastric phase final volume }(m L)}{\text { Gastric emptying duration }(\mathrm{min})}
\end{aligned}
$$

Due to the acidification process found in the stomach, the volume of hydrochloric acid at $1 \mathrm{~mol} \mathrm{~L}^{-1}$ necessary to lower samples to $\mathrm{pH} 2.0$ was quantified by the $\mathrm{pH}$ test tube protocol. For this assay only the fluids of the oral and gastric phases (described below) were added, followed by acidification with hydrochloric acid $1 \mathrm{~mol} \mathrm{~L}^{-1}$. The volume of acid used was then added to the simulated gastric fluid (SGF) mixture during the digestion procedure, allowing a continuous decrease of the $\mathrm{pH}$ as found in vivo. Electrolyte solutions and simulated digestive fluids, specifically SSF, SGF and the simulated intestinal fluid (SIF) constitutions are described in Table 2.

Once these parameters are known, the volumes of enzymes, electrolyte solutions and water to be added in each phase, can be calculated.

\section{Dynamic in vitro gastrointestinal digestion protocol}

The digestion assays in the DIVGIS do not include an oral phase, but it is recommended when solid and/or starchy foods are meant to be tested. Briefly, the protocol can be divided in 5 continuous phases, i.e. oral phase, gastric phase, duodenal phase, jejunal phase and ileal phase. A solution of $30 \%$ starch from potato (w/v) was gelatinised at $85^{\circ} \mathrm{C}$ for $30 \mathrm{~min}$, grinded and submitted to digestion in the DIVGIS to be used as a reference food for the glycemic index determination.

Table 2. Preparation of the electrolyte solutions and simulated digestive fluids. The digestion fluids are prepared $1.25 \mathrm{x}$ concen-

\begin{tabular}{|c|c|c|c|c|c|c|c|c|}
\hline \multirow[b]{3}{*}{ Salts } & & & \multicolumn{2}{|c|}{ SSF (pH 7) } & \multicolumn{2}{|c|}{ SGF (pH 7) } & \multicolumn{2}{|c|}{ SIF (pH 7) } \\
\hline & Stock & rations & $\begin{array}{l}\mathrm{mL} \text { of Stock } \\
\text { added to } \\
\text { prepare }\end{array}$ & Final salt conc. & $\begin{array}{l}\mathrm{mL} \text { of Stock } \\
\text { added to } \\
\text { prepare }\end{array}$ & Final salt conc. & $\begin{array}{l}\mathrm{mL} \text { of Stock } \\
\text { added to } \\
\text { prepare }\end{array}$ & Final salt conc \\
\hline & $g / L$ & $\mathrm{~mol} / \mathrm{L}$ & $\mathrm{mL}$ & $\mathrm{mmol} / \mathrm{L}$ & $\mathrm{mL}$ & $\mathrm{mmol} / \mathrm{L}$ & $\mathrm{mL}$ & $\mathrm{mmol} / \mathrm{L}$ \\
\hline $\mathrm{KCl}$ & 37.3 & 0.5 & 15.1 & 15.1 & 6.9 & 6.9 & 6.8 & 6.8 \\
\hline $\mathrm{KH}_{2} \mathrm{PO}_{4}$ & 68 & 0.5 & 3.7 & 3.7 & 0.9 & 0.9 & 0.8 & 0.8 \\
\hline $\mathrm{NaHCO}_{3}$ & 84 & 1 & 6.8 & 13.6 & 12.5 & 25 & 42.5 & 85 \\
\hline $\mathrm{NaCl}$ & 117 & 2 & - & - & 11.8 & 47.2 & 9.6 & 38.4 \\
\hline $\mathrm{MgCl}_{2}\left(\mathrm{H}_{2} \mathrm{O}\right)_{6}$ & 30.5 & 0.15 & 0.5 & 0.15 & 0.4 & 0.12 & 1.1 & 0.33 \\
\hline$\left(\mathrm{NH}_{4}\right)_{2} \mathrm{CO}_{3}$ & 48 & 0.5 & 0.06 & 0.06 & 0.5 & 0.5 & - & - \\
\hline $\mathrm{CaCl}_{2}\left(\mathrm{H}_{2} \mathrm{O}\right)_{2}$ & 44.1 & 0.3 & - & 1.5 & - & 0.15 & - & 0.6 \\
\hline $\mathrm{H}_{2} \mathrm{O}_{\text {up }}$ & - & - & 373.84 & - & 367 & - & 339.2 & - \\
\hline
\end{tabular}
trated to allow the subsequent addition of enzymes and other solutions. 
The oral phase was performed apart from the DIVGIS. Cooked samples were grinded before incubation at $37^{\circ} \mathrm{C}$ with shaking for $2 \mathrm{~min}$. It consisted in the addition of SSF, $\alpha$-amylase in the concentration required to achieve a final activity of $150 \mathrm{U} / \mathrm{mL}$ (Sigma units) and $\mathrm{CaCl}_{2}\left(\mathrm{H}_{2} \mathrm{O}\right)_{2}$ to achieve $1.5 \mathrm{mmol}$ $\mathrm{L}^{-1}$ to the cooked and grinded samples. Solutions were added in a volume that ensured a 1:1 (w/v) final ratio of dry weight of the food to SSF mixture $\left(\mathrm{SSF}+\right.$ enzyme + water $\left.+\mathrm{CaCl}_{2}\left(\mathrm{H}_{2} \mathrm{O}\right)_{2}\right)$.

The obtained bolus was then placed in the stomach reactor of the DIVGIS to continue the digestion procedure. From this stage onwards, the digestion procedure is dynamic, thus the addition of simulated fluids and enzymes was performed continually using syringe infusion pumps (KDS-100-CE, KD Scientific, Holliston, $\mathrm{MA})$. The solutions were added in a volume that ensured a $1: 1(\mathrm{v} / \mathrm{v})$ final ratio of oral phase content to SGF mixture. SGF mixture was prepared with $4 / 5$ of SGF $(1.25 \times)(\mathrm{v} / \mathrm{v}), \mathrm{CaCl}_{2}\left(\mathrm{H}_{2} \mathrm{O}\right)_{2}$ in order to achieve $1.5 \mathrm{mmol} \mathrm{L}^{-1}$ in the final mixture, the volume of hydrochloric acid $1 \mathrm{~mol} \mathrm{~L}^{-1}$ previously quantified, and the remaining volume of purified water. The enzyme gastric solution was prepared with $10 \mathrm{~mL}$ of the SGF $(1.25 \times)$, volume to be added separately of the SGF mixture. This solution contained $5 \mathrm{~mL}$ of pepsin in SGF with the concentration required to achieve a final activity of $4000 \mathrm{U} /$ $\mathrm{mL}$ (Sigma units) and $5 \mathrm{~mL}$ of lipase in SGF with the concentration required to achieve a final activity of $120 \mathrm{U} / \mathrm{mL}$ (Sigma units). To reproduce the fasting volume of the gastric phase, $10 \%$ of the total amount of SGF mix to be added in the gastric phase (without enzymes) was placed in the stomach reactor prior to the sample. This is called the gastric basal volume. The delivering rate for the remaining $90 \%$ of SGF mix was determined as described in Equation (4) and the delivering rate of the enzyme gastric solution was determined as described in Equation (5): the duodenum reactor. In this phase, solutions were added in a volume that ensured a 1:1 (v/v) final ratio of gastric chyme to SIF mixture. Pancreatin was prepared in SIF $(1.25 \times)$, in the concentration required to achieve a final activity of $100 \mathrm{U} / \mathrm{mL}$ (TAME) and added to the SIF mixture containing $4 / 5$ of SIF $(1.25 \times)(\mathrm{v} / \mathrm{v}), \mathrm{CaCl}_{2}\left(\mathrm{H}_{2} \mathrm{O}\right)_{2}$ to achieve $1.5 \mathrm{mmol} \mathrm{L} \mathrm{L}^{-1}$ in the final mixture and the remaining volume of purified water. Also, a porcine bile solution $10 \mathrm{mmol}$ $\mathrm{L}^{-1}$ was prepared with SIF $(1.25 \times)$. This solution represented $10 \%$ of the SIF mix volume to be added and was delivered separately. The delivering rate for the SIF mix was determined as described in Equation (6) and the delivering rate of the porcine bile solution was determined as described in Equation (7):

$$
\text { SIF mix rate }\left(\frac{m L}{\text { min }}\right)=S G F \text { mix rate }\left(\frac{m L}{\min }\right) * 0.9
$$

SIF mix rate $\left(\frac{m L}{\text { min }}\right)=S G F$ mix rate $\left(\frac{m L}{\text { min }}\right) * 0.1$

In the jejunal and ileal phases, no secretions were added, but both reactors were coupled to MiniKros Sampler hollow fibre filters (S02-E001-05-N, Repligen, Amsterdam, Netherlands) controlled by peristaltic pumps (120S, Watson-Marlow, Concord, Canada). These membranes filtered the soluble portion, and other small molecules, from the digested samples. During the digestion procedure, endpoint samples were collected at the end of each phase, as well as the filtrate portions from the membranes coupled to the jejunum and ileum reactor and the ileum delivery (portion not filtrated or undigested sample).

For each formulation, the digestion assay has been performed at least in triplicate.

$$
S G F \text { mix rate }\left(\frac{m L}{m i n}\right)=\frac{S G F(m L)-\text { Gastric basal volume }(m L)-\text { Enzyme gastric solution }(m L)}{\text { Gastric emptyin }(\text { min })}
$$

$$
\begin{aligned}
& \text { Enzyme gastric solution rate }(\mathrm{mL} / \mathrm{min}) \\
& =\frac{\text { Sample caloric content }(\mathrm{kcal})}{\text { Sample energy rate }(\mathrm{kcal} / \mathrm{min})}
\end{aligned}
$$

The content in the stomach reactor was emptied at the predetermined rate (described in Equation (3)) to

\section{Quantification of released sugars and determination of glycemic index}

D-Glucose from the samples collected in the DIVGIS were quantified using GOPOD reagent enzymes (Megazyme, Wicklow, Ireland). The principle applied to this colorimetric reaction is the conversion of $\mathrm{D}$ glucose to $\mathrm{D}$-gluconate by the glucose oxidase 
Table 3. Total starch, amylose and amylopectin content of Nutriminuto rice formulations.

\begin{tabular}{lccc}
\hline Sample & Total starch (\%) & Amylose (\%) & Amylopectin (\%) \\
\hline BR & $32.38 \pm 1.02^{\mathrm{a}}$ & $10.88 \pm 0.57^{\mathrm{a}}$ & $21.50 \pm 1.16^{\mathrm{a}, \mathrm{b}}$ \\
Q & $32.42 \pm 0.59^{\mathrm{a}}$ & $9.30 \pm 0.57^{\mathrm{a}}$ & $23.12 \pm 0.82^{\mathrm{a}}$ \\
WM & $33.66 \pm 1.36^{\mathrm{a}}$ & $10.11 \pm 0.92^{\mathrm{a}}$ & $23.59 \pm 2.13^{\mathrm{a}}$ \\
VS & $23.73 \pm 1.39^{\mathrm{b}}$ & $5.36 \pm 0.94^{\mathrm{b}}$ & $18.37 \pm 1.67^{\mathrm{b}}$ \\
\hline
\end{tabular}

Mean values within the same column, labelled with the same superscript letter ( $\mathrm{a}$ or $\mathrm{b}$ ) do not statistically differ from each other ( $p$ Value $>0.05$ ).

releasing oxygen peroxide molecules. These molecules are then consumed by peroxidases together with $p$ hydroxybenzoic acid and 4-aminoantipyrine to produce a pink colour quinoneimine dye. Therefore, samples were centrifuged $1800 \mathrm{~g}$ for $10 \mathrm{~min}$ to precipitate large particles. Then $3 \mathrm{~mL}$ of GOPOD reagent was added to $0.1 \mathrm{~mL}$ of supernatant and incubated at $50{ }^{\circ} \mathrm{C}$ for $20 \mathrm{~min}$. After incubation, the absorbance of samples was read at $510 \mathrm{~nm}$. The percentage of glucose was calculated as the quantity of glucose determined in the total initial amount of food. The percentage of glucose released, was then normalised to the percentage of hydrolysed carbohydrates to obtain the area under the curve (AUC) for determination of glycemic index. AUC for formulations and the reference food were calculated in the statistical software GraphPad Prism version 7.04 (GraphPad, La Jolla, $\mathrm{CA}$ ) and used to determine the hydrolysis index (HI) which was applied to determine glycemic index as described in Equations (8) and (9) (Goñi et al. 1997):

$$
\begin{gathered}
H I=\frac{A U C \text { formulation }}{\text { AUC reference food }} * 100 \\
G I=39.71+(H I * 0.549)
\end{gathered}
$$

\section{Statistical analysis}

Statistical analysis was performed in the statistical software GraphPad Prism version 7.04. One-way ANOVA, followed by Tukey's multiple comparison $t$ test with alpha $=0.05$ was used for the statistical analysis of total starch, amylose, amylopectin content between samples as well as TPA parameters. Statistical significance of hydrolysed carbohydrates during digestion was determined using the Holm-Sidak method, with alpha $=0.05$. The principal component analysis (PCA), the box plot and Pearson correlation matrix, with a 2-tailed test of significance with alpha $=0.05$ to obtain the significance level of the correlation coefficients, were obtained using Origin Pro 2018 (OriginLab Corporation, Northampton, MA).

\section{Results and discussion}

Total starch, amylose and amylopectin content of rice formulations

The rice formulations tested consisted in commercially available products, hence their nutrition label was available and is reproduced in Table 1. However, only the amounts of macronutrients, salt and energetic value are detailed. Since this food product has a cereal basis, it is important to know how much of the available carbohydrates correspond to starch. Total starch content as well as the amylose and amylopectin content are presented in Table 3.

Values of total starch obtained for samples are low because they correspond to the percentage of starch found in the totality of the samples, which are constituted by approximately $50 \%$ of rice. Therefore, if the obtained values were converted to dry basis, the total starch percentages would be between $60 \%$ and $70 \%$, which is in accordance with the values found in the literature for this type of rice (Frei et al. 2003; Deepa et al. 2010; Chang et al. 2014). Total starch of VS formulation was lower and presented a statistically significant difference $(p$ Value $<0.05)$ compared to the other formulations, because of its lower quantity of rice (i.e. 41\%). As a consequence, this formulation also presented a significantly lower $(p$ Value $<0.05)$ value of amylose. It was described that lower amylose content in rice is linked to higher retrogradation and to a pastier texture after cooking (Roy et al. 2008; Syahariza et al. 2013).

The results obtained also allow understanding how much of the carbohydrates present in the samples are in the form of starch. In the case of BR, carbohydrates are provided from rice itself (i.e. $97.53 \pm 3.06 \%(\mathrm{w} / \mathrm{w})$ ), whereas in the other formulations, starch only accounts for $83.55 \pm 1.52, \quad 85.22 \pm 4.87$ and $78.07 \pm 4.56 \%$ (Q, WM and VS, respectively) of the available carbohydrates. These formulations contain higher amounts of carbohydrates in the form of reducing sugars or fibres, as shown in Table 1.

\section{Texture profile analysis}

The TPA was performed to correlate textural data with the nutritional and physiochemical characteristics of rice samples and to evaluate how the addition of food ingredients can influence the textural characteristics of rice. The results of TPA are presented in Table 4.

The results in Table 4 allow concluding that the addition of vegetables significantly changed ( $p$ Value 
Table 4. TPA results of the different rice sample formulations.

\begin{tabular}{lcccccc}
\hline Sample & Hardness (g of force) & Adhesiveness (g of force) & Springiness & Cohesiveness & Chewiness & Resilience \\
\hline BR & $17133.81 \pm 3034.34^{\mathrm{a}}$ & $-3.66 \pm 2.16^{\mathrm{a}}$ & $0.91 \pm 0.03^{\mathrm{a}}$ & $0.61 \pm 0.01^{\mathrm{a}}$ & $9074.43 \pm 1703.43^{\mathrm{a}}$ & $0.40 \pm 0.01^{\mathrm{a}}$ \\
Q & $18830.10 \pm 2265.07^{\mathrm{a}, \mathrm{b}}$ & $-2.05 \pm 0.87^{\mathrm{a}}$ & $0.86 \pm 0.05^{\mathrm{a}}$ & $0.60 \pm 0.02^{\mathrm{a}}$ & $10386.33 \pm 797.65^{\mathrm{a}}$ & $0.43 \pm 0.02^{\mathrm{a}}$ \\
WM & $21235.89 \pm 1409.84^{\mathrm{b}}$ & $-1.50 \pm 0.79^{\mathrm{a}}$ & $0.88 \pm 0.06^{\mathrm{a}}$ & $0.59 \pm 0.02^{\mathrm{a}}$ & $10912.80 \pm 1625.78^{\mathrm{a}}$ & $0.42 \pm 0.02^{\mathrm{a}}$ \\
VS & $3918.49 \pm 1827.99^{\mathrm{c}}$ & $-13.80 \pm 7.17^{\mathrm{b}}$ & $0.68 \pm 0.07^{\mathrm{b}}$ & $0.35 \pm 0.05^{\mathrm{b}}$ & $896.53 \pm 560.85^{\mathrm{b}}$ & $0.14 \pm 0.06^{\mathrm{b}}$ \\
\hline
\end{tabular}

Values within the same column that present the same superscript letters $(a, b$ or $c$ ), do not significantly differ ( $p$ Value $<0.05$ ) from each other.

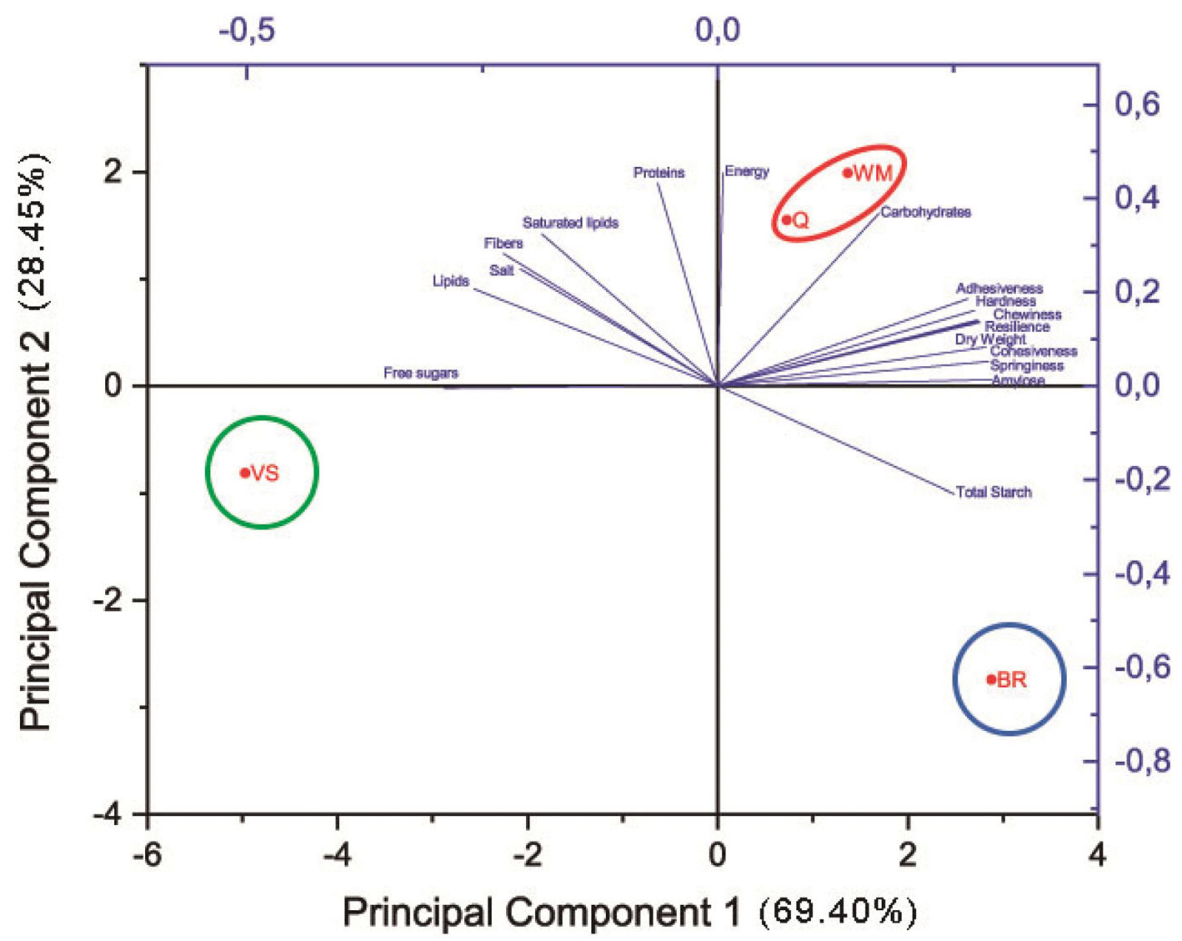

Figure 1. PCA biplot of textural and physicochemical/nutritional variables.

$<0.05)$ the textural profile of rice samples. This change in the profile can be mainly attributed to the presence of peas in the rice samples, which present lower hardness, springiness, cohesiveness, resilience and chewiness. It is also possible to observe that the hardness value of BR samples is significantly different $(p$ Value $<0.05)$ from that of WM samples. This difference can be attributed to the presence of cereal ingredients.

To further understand the relationship of these textural parameters with the rice samples' characteristics, a PCA was performed and the result is represented in Figure 1.

It is possible to observe from the PCA that principal component 1 (PC1) and principal component 2 (PC2) explain, cumulatively, $97.85 \%$ of the total variability of the variables in study. It is also possible to associate $\mathrm{PC} 1$ to textural profile parameters, amylose content, dry weight and free sugars, while PC2 accounts for protein content and energy of rice samples. The remaining variables are associated to both PCs. Moreover, it is also possible to distinguish three groups in the scores plot (i.e. dots). A group consisting of BR samples, a group consisting of WM and $\mathrm{Q}$ samples and a group consisting of VS samples. These groups are also more closely correlated to their main nutritional variables, i.e. $\mathrm{BR}$ is correlated to total starch, which constitutes $97.53 \pm 3.06$ of its carbohydrates, WM and Q are correlated to energy and carbohydrates and VS is correlated to free sugars. However, since PC1 explains most of the data variation, differences among the PC1 axis are more important than those observed in the PC2 axis. Therefore, despite the differences between BR, Q and WM samples, the VS samples present more significant differences when compared with the other formulations. In fact, this correlates with the significant differences observed in the TPA parameters. Taking this into account, the textural characteristics of rice samples are highly correlated with the amylose and dry weight content. To evaluate the significance of the variable correlations, a Pearson correlation matrix was calculated, and the results are presented in Table 5. Table 5 shows that dry weight and amylose content 
Table 5. Pearson's correlation coefficient of selected variables.

\begin{tabular}{|c|c|c|c|c|c|c|c|c|}
\hline & Dry weight & Amylose & Hardness & Adhesiveness & Springiness & Cohesiveness & Chewiness & Resilience \\
\hline Dry weight & - & & & & & & & \\
\hline Amylose & 0.95836 & - & 0.94019 & 0.9161 & 0.99452 & 0.97209 & 0.95964 & 0.94614 \\
\hline Hardness & 0.99828 & 0.94019 & - & 0.99783 & 0.95763 & 0.98112 & 0.99805 & 0.99666 \\
\hline Adhesiveness & 0.99225 & 0.9161 & 0.99783 & - & 0.9367 & 0.97107 & 0.99185 & 0.9937 \\
\hline Springiness & 0.97271 & 0.99452 & 0.95763 & 0.9367 & - & 0.96957 & 0.97292 & 0.95557 \\
\hline Cohesiveness & 0.98686 & 0.97209 & 0.98112 & 0.97107 & 0.96957 & - & 0.98848 & 0.99154 \\
\hline Chewiness & 0.99995 & 0.95964 & 0.99805 & 0.99185 & 0.97292 & 0.98848 & - & 0.99648 \\
\hline Resilience & 0.99586 & 0.94614 & 0.99666 & 0.9937 & 0.95557 & 0.99154 & 0.99648 & - \\
\hline
\end{tabular}

Correlation coefficients coloured in bold present a significant ( $p$ Value $<0.05$ ) correlation between variables.

Table 6. Parameters predetermined for in vitro digestion of Nutriminuto rice formulations on the DIVGIS.

\begin{tabular}{llccccc}
\hline Sample & Dry weight (\%) & $\begin{array}{c}\text { Caloric content } \\
(\mathrm{kcal} / \mathrm{g})\end{array}$ & $\begin{array}{c}\text { Gastric } \\
\text { emptying (min) }\end{array}$ & $\begin{array}{c}\text { Duodenum } \\
\text { emptying (min) }\end{array}$ & $\begin{array}{c}\text { Jejunum filtrate } \\
\text { endpoint } \\
\text { sample (min) }\end{array}$ & $\begin{array}{c}\text { Ileum filtrate/ } \\
\text { delivery endpoint } \\
\text { sample (min) }\end{array}$ \\
\hline BR & $52.27 \pm 0.34$ & 1.717 & 107.31 & 118.0 & 128.8 & 139.5 \\
Q & $52.37 \pm 0.18$ & 2.136 & 133.50 & 146.9 & 160.2 & 173.6 \\
WM & $53.53 \pm 0.13$ & 2.188 & 136.75 & 150.4 & 164.1 & 177.8 \\
VS & $41.20 \pm 0.13$ & 1.877 & 117.94 & 129.7 & 141.5 & 153.3 \\
Starch from potato & 30 & 3.627 & 226.69 & 249.4 & 272.0 & 294.7 \\
$\quad 30 \%$ (w/v) & & & & & & \\
\hline
\end{tabular}

Gastric and duodenum emptying time also correspond to the endpoint sample on those phases.

highly correlate with textural properties. Higher amounts of water (i.e. lower dry matter) in rice formulations translate into softer rice samples. The amylose content positively correlates with springiness, cohesiveness and chewiness (Schirmer et al. 2013; Syahariza et al. 2013; Chen et al. 2017).

\section{Digestion assays using the DIVGIS}

Digestion parameters established for formulations and reference food are described in Table 6.

VS was the sample with higher humidity, affected by the presence of vegetables which yield more than ca. $80 \%$ of water, as opposed to wholegrains which yield ca. $10 \%$ of water (McConnell et al. 1974); accordingly, lower volumes of SSF mix in the oral phase were required for this sample. The protocol applied when using DIVGIS anticipates longer gastric emptying periods when the food has a higher caloric content, as found in in vivo human gastric emptying (Okabe et al. 2017). Also, the gastric emptying is only possible for gastric content with particles smaller than $1 \mathrm{~mm}$. This condition was guaranteed by the addition of a perforated disc in the end of the stomach reactor, representative of the human pylorus, grating both enzymatic and mechanical degradation of samples during the gastric phase. Samples became more viscous over the gastric phase prior transition to succeeding phases. With the continuous addition of hydrochloric acid $1 \mathrm{~mol} \mathrm{~L}^{-1}$ diluted in the SGF mix, $\mathrm{pH}$ decreased until the desired $\mathrm{pH}$ levels (i.e. around 2.0) in one-third of the gastric emptying total duration and remained stable until the end of the gastric phase (data not shown). After completion of the gastric emptying, the succeeding reactors were stopped when no more food digesta or digestive secretions (i.e. fluids and enzymes) were available. Filtration through the hollow fibres was extended until no more food digesta was available.

\section{Hydrolysis of available carbohydrates during digestion}

The GI tract is responsible for the degradation and absorption of macronutrients present in food, which undergoes multiple processes with the purpose of reducing an eventually complex food matrix into monomers, facilitating the absorption of energy and essential compounds (Grand et al. 1976). In this work, rice formulations were digested in vitro and the released D-glucose during these assays was quantified and then converted into percentage of carbohydrates hydrolysed. These results are presented in Figure 2.

Carbohydrates are the major hydrolysed macronutrients due to the combination of mechanical and enzymatic degradation caused by salivary amylases (Woolnough et al. 2010; Bornhorst and Singh 2012). Despite the short time of incubation $(2 \mathrm{~min})$ of the oral phase, the enzymatic action managed a noteworthy impact on the food structure, converting the solid and liquid phase into a mixture, commonly designated as bolus. The formulations tested presented similar degrees of carbohydrate hydrolysis in this 


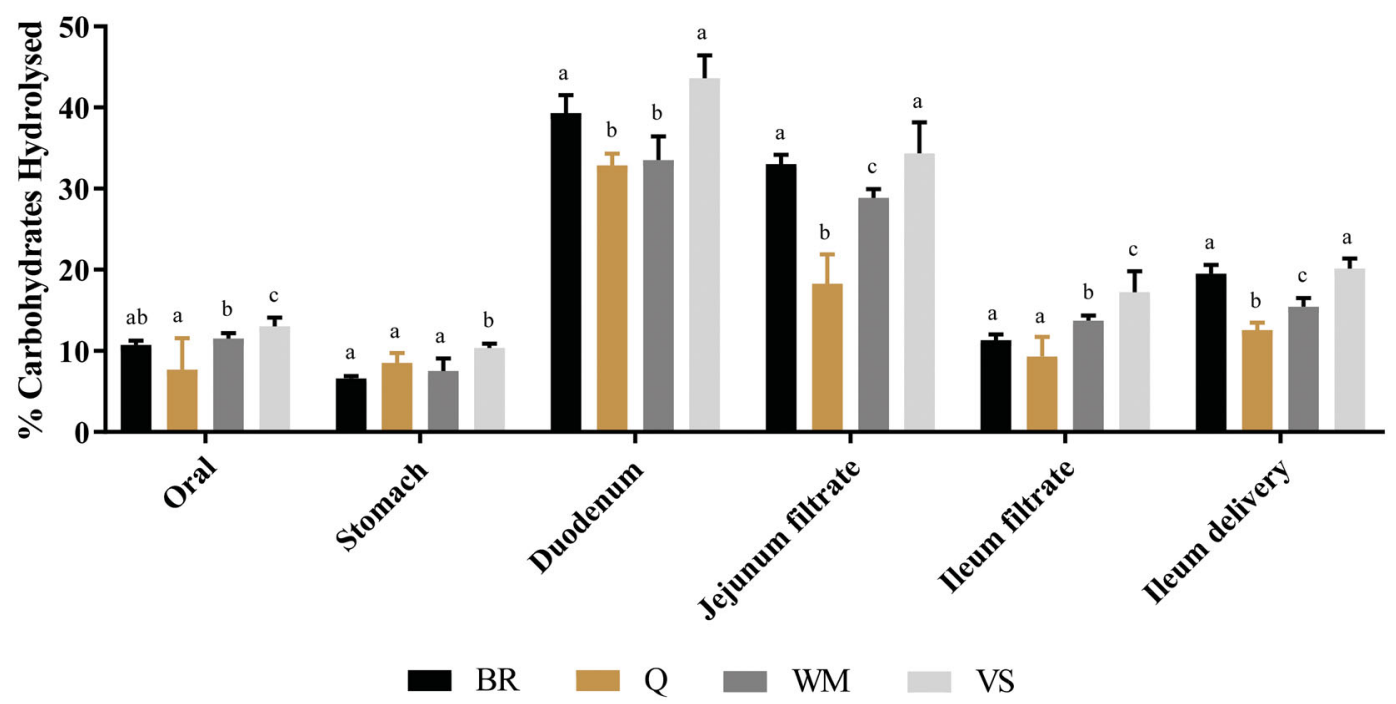

Figure 2. Percentage of carbohydrates hydrolysed during the different phases of in vitro digestion on DIVGIS. Bars represent mean values and the errors bar represents standard deviation. Samples labelled with the same letter $(a, b$ or $c)$ within the same phase of digestion do not statistically differ from each other ( $p$ Value $>0.05$ ).

phase (i.e. $10.71 \pm 0.56,7.69 \pm 3.87,11.51 \pm 0.69$ and $13.02 \pm 1.10 \%$ for BR, Q, WM and VS, respectively).

The gastric phase provoked the main structural degradation on the food. The combination of a longer incubation period, acid conditions and enzymatic action generate partially digested food containing smaller particles. The food digesta resultant from this phase is commonly designated as chyme. During this phase, the percentages of carbohydrates hydrolysed did not increase compared with the results obtained in the oral phase. This result was expected, since the enzymatic action of pepsin and lipase are responsible for breaking down the protein and lipid content of the samples, promoting changes on carbohydrate structures, without specifically degrading them or releasing glucose (Freitas et al. 2018). On the other hand, the samples collected in the end of the duodenal phase had high percentage of hydrolysed carbohydrates. In addition to the chemical and mechanical digestion of chyme, the addition of pancreatin and bile salts, as well as the neutralisation of medium $\mathrm{pH}$, gathered the optimal conditions for pancreatic amylases action (Sundarram et al. 2014). BR and VS formulations presented higher hydrolysis at the end of the duodenal phase compared to the samples containing wholegrains (i.e. $39.31 \pm 2.20, \quad 32.87 \pm 1.44$, $33.50 \pm 2.93$ and $43.60 \pm 2.84 \%$ for $\mathrm{BR}, \mathrm{Q}, \mathrm{WM}$ and VS, respectively). Also, the passive absorption of glucose in the jejunum presented statistically significant ( $p$ Value $<0.05$ ) lower values for Q and WM samples. Similar results were obtained in the ileum filtrate with the exception of BR formulation, which presented similar results to $\mathrm{Q}$ formulation. The ileum delivery represents the portion of hydrolysed carbohydrates that was not absorbed, and would proceed to the large intestine. Again, formulations containing wholegrains ( $Q$ and WM) had lower quantities of sugars that were not absorbed (i.e. $19.52 \pm 1.08,12.58 \pm 0.89$, $15.42 \pm 1.09$ and $20.14 \pm 1.27 \%$ for $\mathrm{BR}, \mathrm{Q}, \mathrm{WM}$ and VS, respectively).

The addition of cereals, grains, vegetables and seeds in the different formulations affected mainly the type of carbohydrates present in the samples (i.e. free sugars and fibres), leading to changes in the digestibility, glucose release and its absorption, as presented in hydrolysis profiles found in Figure 2.

The addition of wholegrains to rice raised the carbohydrate content of formulations Q and WM (see Table 1), even though it did not change the total starch content in a significant statistically value ( $p$ Value > 0.05) compared to BR (see Table 3). Also, as shown in the PCA (Figure 1), Q and WM had a worst correlation with free sugars, suggesting that the higher amount of carbohydrates was indeed due to fibres from the added wholegrains. Nevertheless, despite higher amounts of carbohydrates were present, the hydrolysis of available carbohydrates was significantly lower ( $p$ Value $<0.05$ ) for Q and WM formulations. This result suggests that dietary fibres present in these formulations (i.e. quinoa, buckwheat, millet and chia) were more resistant to hydrolysis when compared to cereals alone (i.e. brown rice) (Cui et al. 2013).

In contrast, the addition of veggies and seeds in VS formulation maintained the carbohydrates content at the same level of BR (see Table 1), however, the total starch value (see Table 3) was significantly lower 


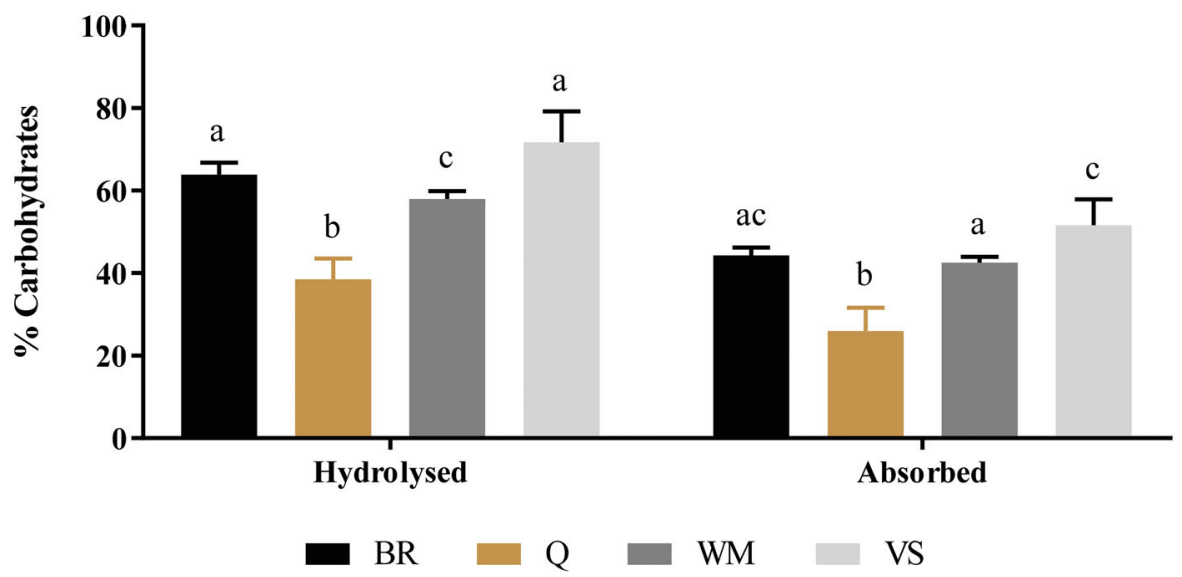

Figure 3. Percentage of total carbohydrates hydrolysed and absorbed in the in vitro digestion on DIVGIS. Bars represent mean values and the errors bar represents standard deviation. Samples labelled with the same letter $(a, b$ or $c)$ within the same phase of digestion do not statistically differ from each other ( $p$ Value $>0.05$ ).

( $p$ Value $<0.05$ ). This formulation presented the highest values for hydrolysis of available carbohydrates throughout all the in vitro digestive process, in spite of presenting the highest fibres content of all formulations. This result can be correlated to VS higher free sugar content, which can also be correlated to its higher water content and lower chewiness (see Figure 1) (Rahman and Al-Farsi 2005).

The results obtained prove that a controlled glucose release could be achieved by the addition of different ingredients. As said above, the addition of wholegrains reduced the amount of glucose release from the base food (i.e. brown rice). This outcome is of upmost interest when lower amounts of sugars are intended, such as the case of obese populations. On the contrary, the addition of vegetables increased the amount of glucose released from the same base food.

\section{Glucose bioaccessibility and glycemic index of formulations}

Absorption of glucose released during in vitro digestion is presented in Figure 3. This parameter can be considered as the bioaccessibility of glucose, since it describes the quantity of glucose that was released from a food formulation and that permeated through jejunal and ileal membranes, representing the intestinal absorption of compounds that become accessible to be used in the physiological functions (Ribnicky et al. 2014).

Formulation Q had the lower bioaccessibility of glucose, followed by WM, BR and VS, respectively. This formulation presents a higher fibre content comparing to $\mathrm{WM}$ and BR (see Table 1), which was more resistant to hydrolysis and obtained lower values of glucose absorbed. On the contrary, VS contained higher fibre content compared with $\mathrm{Q}$, that said its amylose content was significantly lower than all the other formulations, which translates to a starch more prone to hydrolysis. Other contributing factor for the lower glucose bioaccessibility in formulation $\mathrm{Q}$ is the presence of antinutrients from quinoa, that present inhibitory effects on $\alpha$-amylase and $\alpha$-glucosidase activities (Hemalatha et al. 2016). Yet, the addition of quinoa did not alter the textural profile of the sample, whereas the addition of vegetables in VS reduced the sample hardness and, consequently, its chewiness which results in an increase of free glucose and, thereafter higher glucose bioaccessibility. Lower absorption of glucose is desired since it will result in lower glycemic index values. The glycemic index of the tested rice formulations were $64.66 \pm 0.44$, $63.13 \pm 4.94,71.02 \pm 1.56,73.52 \pm 1.95$ for BR, Q, WM and $\mathrm{VS}$, respectively. Therefore, $\mathrm{BR}$ and $\mathrm{Q}$ are classified as medium glycaemic index food, while WM and VS are classified as high glycaemic index foods (Brand-Miller et al. 2002). These results are in accordance with values found in the literature (Chang et al. 2014; Zenel and Stewart 2015; Kaur et al. 2016), validating the results obtained using the DIVGIS for in vitro dynamic digestion assays.

\section{Conclusions}

The addition of ingredients to wholegrain rice significantly changed the digestive rate of formulations. These differences were resultant of the different nutrients available in the formulations, which presented higher values of carbohydrates, free sugars, lipids, proteins and fibres. The addition of wholegrains, specially quinoa, increased carbohydrates in formulation $\mathrm{Q}$ and WM, nevertheless the carbohydrates hydrolysis was lower for these formulations and correlated with their higher fibre content. The addition of vegetables in VS formulation had the opposed impact, resulting in higher hydrolysis of available 
carbohydrates that can be correlated to more free sugars present and to lower chewiness. Further studies are needed to deeply evaluate the role of different ingredients (i.e. dietary fibres, sugars, proteins, lipids) on other rice varieties and how this can better correlate with the sensory and textural profile of rice. However, this work glances this topic with some relevant insights regarding the influence of food ingredients, of different types and sources, in rice in vitro digestion kinetics. Also, understanding how ingredients affect the digestibility of food is of upmost importance, since they could allow a controlled glucose release in far more simple and economical way, helping us manage human sugar consumption. The application of dynamic in vitro gastrointestinal systems for simulation of food digestion allows acquiring knowledge and withdrawing conclusions of their hydrolysis profile and determining how different food structures may influence bioaccessibility of nutrients and bioactive compounds, since these components can alter food texture and, therefore, its behaviour and kinetics during digestion.

\section{Acknowledgements}

Daniel A. Madalena acknowledges the Foundation for Science and Technology (FCT) for his fellowship (SFRH/ $\mathrm{BD} / 129127 / 2017)$. The authors would also like to thank the investment project $\mathrm{n}^{\circ} 017931$ - Development of rice products with low glycemic index- co-funded by Fundo Europeu de Desenvolvimento Regional (FEDER) through Programa Operacional Competitividade e Internacionalização (COMPETE 2020) (POCI-01-0247-FEDER-017931).

\section{Disclosure statement}

The authors wish to confirm that there are no known conflicts of interest associated with this publication and there has been no significant financial support for this work that could have influenced its outcome.

\section{Funding}

This study was supported by the Portuguese Foundation for Science and Technology(FCT) under the scope of the strategic funding of UIDB/04469/2020 unit and BioTecNorte operation [NORTE-01-0145-FEDER-000004] funded by the European Regional Development Fund under the scope of Norte2020 - Programa Operacional Regional do Norte.

\section{References}

Alonso R, Aguirre A, Marzo F. 2000. Effects of extrusion and traditional processing methods on antinutrients and in vitro digestibility of protein and starch in faba and kidney beans. Food Chem. 68(2):159-165.

Azizi R, Capuano E, Nasirpour A, Pellegrini N, Golmakani MT, Hosseini SMH, Farahnaky A. 2019. Varietal differences in the effect of rice ageing on starch digestion. Food Hydrocoll. 95 (March):358-366.

Boers HM, Seijen Ten Hoorn J, Mela DJ. 2015. A systematic review of the influence of rice characteristics and processing methods on postprandial glycaemic and insulinaemic responses. Br J Nutr. 114(7):1035-1045.

Bornhorst GM, Singh RP. 2012. Bolus formation and disintegration during digestion of food carbohydrates. Compr Rev Food Sci Food Saf. 11(2):101-118.

Brand-Miller JC, Holt SH, Pawlak DB, McMillan J. 2002. Glycemic index and obesity. Am J Clin Nutr. 76(1): 281S-285S.

Brodkorb A, Egger L, Alminger M, Alvito P, Assunção R, Ballance S, Bohn T, Bourlieu-Lacanal C, Boutrou R, Carrière F, et al. 2019. INFOGEST static in vitro simulation of gastrointestinal food digestion. Nat Protoc. 14(4): 991-1014.

Calbet JAL, MacLean DA. 1997. Role of caloric content on gastric emptying in humans. J Physiol. 498(2):553-559.

Chang UJ, Hong YH, Jung EY, Suh HJ. 2014. Rice and the glycemic index. In: Wheat and rice in disease prevention and health. San Diego (CA): Academic Press; p. 357-363.

Chen X, Du X, Chen P, Guo L, Xu Y, Zhou X. 2017. Morphologies and gelatinization behaviours of highamylose maize starches during heat treatment. Carbohydr Polym. 157:637-642.

Cui SW, Wu Y, Ding H. 2013. The range of dietary fibre ingredients and a comparison of their technical functionality. In: Delcour JA, Kaisa Poutanen, editors. Fibre-rich and wholegrain foods: improving quality. New York: Elsevier Ltd; p. 96-119.

Deepa G, Singh V, Naidu KA. 2010. A comparative study on starch digestibility, glycemic index and resistant starch of pigmented ("Njavara" and 'Jyothi') and a non-pigmented ('IR 64') rice varieties. J Food Sci Technol. 47(6): 644-649.

Dhingra D, Michael M, Rajput H, Patil RT. 2012. Dietary fibre in foods: a review. J Food Sci Technol. 49(3): 255-266.

European Parliament. 2011. Regulation (EU) no. 1169/2011 of the European Parliament and of the Council of 25 October 2011 on the provision of food information to consumers. Off J Eur Union. 304:18-63. doi:2004R0726 v.7 of 05.06.2013.

Fernandes J, Madalena DA, Pinheiro AC, Vicente AA. 2020. Rice in vitro digestion: application of INFOGEST harmonized protocol for glycemic index determination and starch morphological study. J Food Sci Technol. 57(4):1393-1404.

Filho AMM, Pirozi MR, Borges JTDS, Pinheiro Sant'Ana HM, Chaves JBP, Coimbra JSDR. 2017. Quinoa: nutritional, functional, and antinutritional aspects. Crit Rev Food Sci Nutr. 57(8):1618-1630.

Frei M, Siddhuraju P, Becker K. 2003. Studies on the in vitro starch digestibility and the glycemic index of six different indigenous rice cultivars from the Philippines. Food Chem. 83(3):395-402. 
Freitas D, Le Feunteun S, Panouillé M, Souchon I. 2018. The important role of salivary $\alpha$-amylase in the gastric digestion of wheat bread starch. In: Food and function. 9(1):200-208.

Goñi I, Garcia-Alonso A, Saura-Calixto F. 1997. A starch hydrolysis procedure to estimate glycemic index. Nutr Res. 17(3):427-437.

Grand RJ, Watkins JB, Torti FM. 1976. Development of the human gastrointestinal tract: a review. Gastroenterology. 70(5):790-810.

Grundy MML, Edwards CH, Mackie AR, Gidley MJ, Butterworth PJ, Ellis PR. 2016. Re-evaluation of the mechanisms of dietary fibre and implications for macronutrient bioaccessibility, digestion and postprandial metabolism. Br J Nutr. 116(5):816-833.

Gularte MA, Gómez M, Rosell CM. 2012. Impact of legume flours on quality and in vitro digestibility of starch and protein from gluten-free cakes. Food Bioprocess Technol. 5(8):3142-3150.

Hemalatha P, Bomzan DP, Sathyendra Rao BV, Sreerama YN. 2016. Distribution of phenolic antioxidants in whole and milled fractions of quinoa and their inhibitory effects on $\alpha$-amylase and $\alpha$-glucosidase activities. Food Chem. 199:330-338.

Jha SK, Singh HR, Prakash P. 2017. Dietary fiber and human health: an introduction. in: dietary fiber for the prevention of cardiovascular disease: fiber's interaction between gut micoflora, sugar metabolism, weight control and cardiovascular health. New York: Elsevier Inc. p. $1-22$.

Kaur B, Ranawana V, Henry J. 2016. The glycemic index of rice and rice products: a review, and Table of GI Values. Crit Rev Food Sci Nutr. 56(2):215-236.

McConnell AA, Eastwood MA, Mitchell WD. 1974. Physical characteristics of vegetable foodstuffs that could influence bowel function. J Sci Food Agric. 25(12):1457-1464.

Minekus M, Alminger M, Alvito P, Ballance S, Bohn T, Bourlieu C, Carrière F, Boutrou R, Corredig M, Dupont $\mathrm{D}$, et al. 2014. A standardised static in vitro digestion method suitable for food -an international consensus. Food Funct. 5(6):1113-1124.

Mulet-Cabero A-I, Egger L, Portmann R, Ménard O, Marze S, Minekus M, Le Feunteun S, Sarkar A, Grundy MM-L, Carrière F, et al. 2020. A standardised semi-dynamic in vitro digestion method suitable for food -an international consensus. Food Funct. 11(2):1702-1720.

Nakov G, Jukić M, Vasileva N, Stamatovska V, Dimov I, Komlenić DK. 2019. The influence of different sweeteners on in vitro starch digestion in biscuits with wheat flour and whole barley flour. Sci Study Res Chem Chem Eng Biotechnol Food Ind. 20(1):53-62.

Okabe T, Terashima H, Sakamoto A. 2017. A comparison of gastric emptying of soluble solid meals and clear fluids matched for volume and energy content: a pilot crossover study. Anaesthesia. 72(11):1344-1350.

Opazo-Navarrete M, Tagle Freire D, Boom RM, Janssen A. 2019. The influence of starch and fibre on in vitro protein digestibility of dry fractionated Quinoa Seed (Riobamba Variety). Food Biophys. 14(1):49-59.

Palafox-Carlos H, Ayala-Zavala JF, González-Aguilar GA. 2011. The role of dietary fiber in the bioaccessibility and bioavailability of fruit and vegetable antioxidants. J Food Sci. 76(1):R6-R15.

Patindol JA, Siebenmorgen TJ, Wang Y-J. 2015. Impact of environmental factors on rice starch structure: a review. Starch - Stärke. 67(1-2):42-54.

Pinheiro AC, Coimbra MA, Vicente AA. 2016. In vitro behaviour of curcumin nanoemulsions stabilized by biopolymer emulsifiers - effect of interfacial composition. Food Hydrocoll. 52:460-467.

Rahman MS, Al-Farsi SA. 2005. Instrumental texture profile analysis (TPA) of date flesh as a function of moisture content. J Food Eng. 66(4):505-511.

Reed MO, Ai Y, Leutcher JL, Jane J. 2013. Effects of cooking methods and starch structures on starch hydrolysis rates of rice. J Food Sci. 78(7):H1076-H1081.

Ribnicky DM, Roopchand DE, Oren A, Grace M, Poulev A, Lila MA, Havenaar R, Raskin I. 2014. Effects of a high fat meal matrix and protein complexation on the bioaccessibility of blueberry anthocyanins using the TNO gastrointestinal model (TIM-1). Food Chem. 142: 349-357.

Roy P, Ijiri T, Okadome H, Nei D, Orikasa T, Nakamura N, Shiina T. 2008. Effect of processing conditions on overall energy consumption and quality of rice (Oryza sativa L.). J Food Eng. 89(3):343-348.

Schirmer M, Höchstötter A, Jekle M, Arendt E, Becker T. 2013. Physicochemical and morphological characterization of different starches with variable amylose/amylopectin ratio. Food Hydrocoll. 32(1):52-63.

Shapter FM, Henry RJ, Lee LS. 2008. Endosperm and starch granule morphology in wild cereal relatives. Plant Genet Res. 6(02):85-97.

Sundarram A, Pandurangappa T, Murthy K. 2014. $\alpha$-Amylase production and applications: a review. J Appl Environ Microbiol. 2(4):166-175.

Świeca M, Seczyk Ł, Gawlik-Dziki U, Dziki D. 2014. Bread enriched with quinoa leaves - the influence of proteinphenolics interactions on the nutritional and antioxidant quality. Food Chem. 162:54-62.

Syahariza ZA, Sar S, Hasjim J, Tizzotti MJ, Gilbert RG. 2013. The importance of amylose and amylopectin fine structures for starch digestibility in cooked rice grains. Food Chem. 136(2):742-749.

Tamura M, Singh J, Kaur L, Ogawa Y. 2016. Impact of structural characteristics on starch digestibility of cooked rice. Food Chem. 191:91-97.

Wong THT, Louie J. 2017. The relationship between resistant starch and glycemic control: a review on current evidence and possible mechanisms. Starch/Staerke. 69:7-8.

Woolnough JW, Bird AR, Monro JA, Brennan CS. 2010. The effect of a brief salivary $\alpha$-amylase exposure during chewing on subsequent in vitro starch digestion curve profiles. IJMS. 11(8):2780-2790.

Yu L, Turner MS, Fitzgerald M, Stokes JR, Witt T. 2017. Review of the effects of different processing technologies on cooked and convenience rice quality. Trends Food Sci Technol. 59:124-138.

Zenel AM, Stewart ML. 2015. High amylose white rice reduces post-prandial glycemic response but not appetite in humans. Nutrients. 7(7):5362-5374. 